\title{
Protective effect of hydrogen sulfide on monocrotaline-induced pulmonary arterial hypertension via inhibition of the endothelial mesenchymal transition
}

\author{
HUI ZHANG ${ }^{1}$, YANJUN LIN ${ }^{1}$, YIWEN MA ${ }^{2}$, JUNFENG ZHANG $^{1}$, CHANGQIAN WANG $^{1}$ and HUILI ZHANG ${ }^{1}$ \\ Departments of ${ }^{1}$ Cardiology and ${ }^{2}$ Anesthesiology, Shanghai Ninth People's Hospital, \\ Shanghai Jiaotong University School of Medicine, Shanghai 200011, P.R. China
}

Received June 9, 2019; Accepted September 9, 2019

DOI: $10.3892 /$ ijmm.2019.4359

\begin{abstract}
Endothelial-to-mesenchymal transition (EndMT) serves an important role in the vascular remodeling of pulmonary arterial hypertension (PAH). However, little is known about the correlation between hydrogen sulfide $\left(\mathrm{H}_{2} \mathrm{~S}\right)$, a protective gaseous mediator in PAH and the process of EndMT. Male Sprague-Dawley rats (10 weeks old) received a single dose of monocrotaline (MCT; i.p., $60 \mathrm{mg} / \mathrm{kg}$ ) and were randomly treated with $\mathrm{NaHS}$ [an $\mathrm{H}_{2} \mathrm{~S}$ donor; intraperitoneal (i.p.) $1 \mathrm{mg} / \mathrm{kg} /$ day], DL-propagylglycine (an inhibitor of $\mathrm{H}_{2} \mathrm{~S}$ synthesis; PAG; i.p., $10 \mathrm{mg} / \mathrm{kg} /$ day) or saline, 7 days after MCT injection. Rats were sacrificed 21 days after MCT injection. A selection of human pulmonary artery endothelial cells (HPAECs) were pretreated with NaHS or saline and stimulated with transforming growth factor (TGF)- $\beta 1(10 \mathrm{ng} / \mathrm{ml})$, and the other HPAECs were transfected with a cystathionine $\gamma$-lyase (CSE, an $\mathrm{H}_{2} \mathrm{~S}$ synthesizing enzyme) plasmid and subsequently stimulated with TGF- $\beta 1$. NaHS was indicated to inhibit EndMT and PAH progression by inhibiting the induction of the nuclear factor (NF)- $\mathrm{BB}-$ Snail pathway. In contrast, the depletion of $\mathrm{H}_{2} \mathrm{~S}$ formation by PAG exacerbated EndMT and PAH by activating NF- $\mathrm{BB}-$ Snail molecules. In HPAECs, NaHS dose-dependently inhibited TGF- $\beta 1$-induced EndMT and the activation of the NF- $\kappa \mathrm{B}-$ Snail pathway. Transfection with a CSE plasmid significantly repressed TGF- $\beta 1$-induced expression of the mesenchymal marker and upregulated the expression of the endothelial marker, which was accompanied by the suppression of the NF- $\kappa \mathrm{B}-$ Snail pathway. The inhibitory effect of CSE overexpression on TGF- $\beta 1$-induced EndMT was significantly reversed by pretreatment with PAG. In
\end{abstract}

Correspondence to: Dr Huili Zhang, Department of Cardiology, Shanghai Ninth People's Hospital, Shanghai Jiaotong University School of Medicine, 639 Zhizaoju Road, Shanghai 200011, P.R. China

E-mail: huilizhang815@163.com

Key words: pulmonary arterial hypertension, endothelialto-mesenchymal transition, hydrogen sulfide conclusion, the current study provides novel information elucidating the beneficial effect of $\mathrm{H}_{2} \mathrm{~S}$ on $\mathrm{PAH}$ through inhibiting the induction of the NF- $\mathrm{B}$-Snail pathway and the subsequent process of EndMT in pulmonary arteries.

\section{Introduction}

Endothelial-mesenchymal transition (EndMT) is a cellular process whereby endothelial cells (ECs) undergo a change in phenotype toward mesenchymal cells. EndMT results in the upregulation of mesenchymal markers, including $\alpha$-smooth muscle actin (SMA) and vimentin, and the downregulation of EC markers, including vascular endothelial (VE)-cadherin and cluster of differentiation 31 (1). EndMT has been demonstrated to be a key source of mesenchymal cells and an important process in the development of fibrotic diseases (1-4). Despite the indication of EndMT as an important process in numerous animal models of fibrotic diseases, a number of studies have suggested that EndMT may participate in the pathogenesis of pulmonary arterial hypertension (PAH) (5-7). Ranchoux et al (7) obtained in situ evidence of the presence of EndMT in human pulmonary arteries from patients with PAH. This study indicated their findings in a well-established animal model of PAH (monocrotaline and $\mathrm{SuHx}$ ). A study by Hopper et al (6) also identified the occurrence of EndMT in patients with PAH and in animal models. These findings provided convincing experimental evidence that specific therapeutic agents could be used to abrogate the process and may improve the outcome of the patients with PAH.

Hydrogen sulfide $\left(\mathrm{H}_{2} \mathrm{~S}\right)$ is a gaseous mediator and is generated endogenously by cystathionine $\beta$-synthase (EC4.2.1.22) and cystathionine $\gamma$-lyase (CSE; EC4.4.1.1) during cysteine metabolism (8). Endogenous $\mathrm{H}_{2} \mathrm{~S}$ has previously been identified as a gasotransmitter that is associated with physiological actions during cardiovascular regulation, with carbon monoxide and nitric oxide $(9,10)$. For example, it has been suggested that the abnormal generation and dysfunction of $\mathrm{H}_{2} \mathrm{~S}$ serves crucial roles in the development of pulmonary hypertension (11-14). Treatment with exogenous $\mathrm{H}_{2} \mathrm{~S}$ has been indicated to promote apoptosis of pulmonary artery smooth muscle cells (SMCs), inhibit proliferation of pulmonary artery SMCs and reduce collagen deposition, leading to improvement in pulmonary 
vascular remodeling (10-14). However, the link between $\mathrm{H}_{2} \mathrm{~S}$ and pulmonary vascular EndMT in PAH has not yet been fully determined. Therefore, the current study aimed to explore the regulatory role of $\mathrm{H}_{2} \mathrm{~S}$ in EndMT during PAH. Due to the fact monocrotaline (MCT) causes direct endothelial damage and vascular remodeling, and can induce the occurrence of severe and lethal PAH (15), an MCT-induced rodent model was used in the present study. The results indicated that endogenous $\mathrm{H}_{2} \mathrm{~S}$ insufficiency accompanies the process of pulmonary EndMT in MCT-induced PAH. The supplementation of $\mathrm{H}_{2} \mathrm{~S}$ inhibited the activation of the NF- $\mathrm{B}-$ Snail pathway in endothelial cells, resulting in the attenuation of EndMT and PAH. These results revealed that $\mathrm{H}_{2} \mathrm{~S}$ warrants further study as a novel therapeutic target for EndMT in PAH.

\section{Materials and methods}

Animal model. The current study was carried out in accordance with the recommendations in the Guide for the Care and Use of Laboratory Animals of the Shanghai Jiaotong University School of Medicine. The protocol was approved by the Committee on the Ethics of Animal Experiments of the Shanghai Jiaotong University School of Medicine [permit no. (2015)-130]. During the current study, 60 male Sprague-Dawley rats $(250 \pm 15 \mathrm{~g}$; age, 10 weeks), obtained from the Central Laboratory of Shanghai Ninth People's Hospital (Shanghai, China), were kept in sterilized filter top cages with controlled humidity and a 12-h day/night cycle at $22^{\circ} \mathrm{C}$. Standard rat chow and tap water were provided ad libitum. Rats received a single intraperitoneal (i.p.) injection of MCT (60 mg/kg; Sigma-Aldrich; Merck KGaA) to induce PAH. Rats were sacrificed at day 7, 14, 21 and 28 following MCT injection to observe the time-dependent alterations of EndMT and $\mathrm{H}_{2} \mathrm{~S}$ synthesis. Rats were randomly administered NaHS (an $\mathrm{H}_{2} \mathrm{~S}$ donor; i.p., $1 \mathrm{mg} / \mathrm{kg} /$ day), DL-propagylglycine (an inhibitor of $\mathrm{H}_{2} \mathrm{~S}$ synthesis; PAG; i.p., $10 \mathrm{mg} / \mathrm{kg} /$ day), or saline, 7 days after MCT injection (16,17). After a period of 14 days, rats were anesthetized with chloral hydrate (i.p., $400 \mathrm{mg} / \mathrm{kg}$ ) and their blood was collected via cardiac puncture. After observation for $10 \mathrm{~min}$, the death of the animals was confirmed by the presence of cardiac arrest and apnea, which was assessed using a stethoscope. Subsequently, rat lungs were harvested and stored at $-80^{\circ} \mathrm{C}$ for subsequent use. Rat hearts were isolated, washed and weighed using an analytical balance to calculate the weight ratio of the right ventricle to the left ventricle plus septum $[\mathrm{RV} /(\mathrm{LV}+\mathrm{S})]$. At the beginning and the end of the current study, systolic blood pressure was monitored using a non-invasive computerized tail cuff system (Blood Pressure Analysis System BP-98AW monitor; Softron Co., Ltd.).

Cell culture. Human pulmonary artery endothelial cells (HPAECs; ScienCell Research Laboratories, Inc.) cultured in endothelial cell medium (ScienCell Research Laboratories, Inc.) containing 5\% fetal bovine serum (FBS; ScienCell Research Laboratories, Inc.), $100 \mu \mathrm{g} / \mathrm{ml}$ streptomycin, $100 \mathrm{U} / \mathrm{ml}$ penicillin and $1 \%$ endothelial cell growth factor (ScienCell Research Laboratories, Inc.). Cells were plated onto six-well plates or $100 \mathrm{~mm}$ tissue culture dishes $24 \mathrm{~h}$ prior to experimentation. Prior to treatment or stimulation, near-confluent cultures were starved for $\geq 12 \mathrm{~h}$ in medium containing $0.5 \%$ FBS.
Cell treatment. HPAECs at $\sim 80 \%$ confluence were rinsed twice with serum-free culture medium prior to treatment. Cells were pre-incubated with saline or NaHS $(50,100$ or $200 \mu \mathrm{M})$ for $2 \mathrm{~h}$. Cells were then incubated with transforming growth factor (TGF)- $\beta 1(10 \mathrm{ng} / \mathrm{ml})$ for $24 \mathrm{~h}$, in the continuous presence of NaHS, to investigate the activation of the Snail-nuclear factor

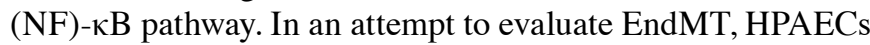
were subsequently incubated with TGF- $\beta 1(10 \mathrm{ng} / \mathrm{ml})$ for an additional 9 days.

Measurement of pulmonary artery pressure and right ventricular hypertrophy. Invasive closed-chest right heart catherization (RHC) was performed to obtain the pulmonary artery pressure. Briefly, animals were anesthetized via i.p., injection of $4 \%$ chloral hydrate $(360 \mathrm{mg} / \mathrm{kg})$. Following the exposure of the right external jugular vein, a polyethylene pipe catheter was inserted. The catheter was then advanced through the superior vena cava, right atrium and right ventricle, into the pulmonary artery. Systolic pulmonary artery pressure, diastolic pulmonary artery pressure and mean pulmonary artery pressure was continuously monitored using ScisenseADV Pressure-Volume Measurement System and LabScribe 2 software (iWORX), using a pressure sensor, which was connected to the extracorporal end of the catheter.

Measurement of right heart function using ultrasound biomicroscopy. Right heart function was measured using an ultrasound biomicroscopy system (Vevo 770; FUJIFILM VisualSonics, Inc.) equipped with a $40 \mathrm{MHz}$ transducer. An apical four-chamber view was used to visualize the tricuspid annular plane systolic excursion (TAPSE), which is a specific echocardiographic parameter of RV function. All tests were performed twice and analyzed by a sonographer who was blinded to the experiment.

Histological examination. After anesthetization, rats were subjected to left ventricle perfusion with $10 \%$ neutralized formalin, at a stable pressure of $100 \mathrm{mmHg}$. The right upper lung was subsequently isolated and processed. Paraffin-embedded lung tissue sections $(5 \mathrm{~mm})$ were stained with hematoxylin for $5 \mathrm{~min}$ and eosin for $2 \mathrm{~min}$ at room temperature. The histology of the muscular arteries (vessels of $\sim 150 \mu \mathrm{m}$ diameter) in the lungs was investigated using a light microscope with an objective lens magnification of $\mathrm{x} 40$ and an eyepiece magnification of x10 (Nikon Corporation). Remodeling of pulmonary arteries was quantified by ImageJ 1.47 software (National Institutes of Health). Lumen area is defined as the area within the lamina elastica interna. The medial area is defined as the area between the lamina elastica interna and the lamina elastica externa. Measurement of media and lumen area of pulmonary arteries was acquired by tracing the border of the lumen, the internal and external elastic laminae. A total of 10 arteries were measured per animal. The average of 10 values obtained was used for calculations. The ratio of media area (MA) to lumen area (LA) was calculated.

Transmission electron microscopy (TEM). For TEM morphological analysis, freshly excised lung tissues or cell pellets were fixed for $2 \mathrm{~h}$ in $2.5 \%$ glutaraldehyde in $0.1 \mathrm{M}$ sodium cacodylate buffer ( $\mathrm{pH} 7.4)$ at room temperature. These were 
then post-fixed with $1 \%$ osmium tetroxide, contrasted with uranyl acetate $2 \%$ in water for $2 \mathrm{~h}$ at $4^{\circ} \mathrm{C}$, dehydrated through a graded ethanol series at $4^{\circ} \mathrm{C}$ and embedded in Epon medium for $4 \mathrm{~h}$ at room temperature. Ultrathin sections $(70 \mathrm{~nm})$ were placed onto 200 mesh cooper grids, and counter stained with lead citrate for $10 \mathrm{~min}$ at room temperature prior to examination using an electron microscope, which was operating at $80 \mathrm{kV}$. Finally, sections were observed using electron microscopy (HT7700; Hitachi, Ltd.).

Western blot analysis. Lungs were homogenized at $4^{\circ} \mathrm{C}$ in radioimmunoprecipitation lysis buffer (Beyotime Institute of Biotechnology). Cultured cells $\left(3 \times 10^{6}\right)$ were lysed at $4^{\circ} \mathrm{C}$ in radioimmunoprecipitation assay lysis buffer. Tissue homogenates or cell lysates were extracted using centrifugation at $14,000 \mathrm{x} \mathrm{g}$ for $10 \mathrm{~min}$ at $4^{\circ} \mathrm{C}$. The protein concentration was assayed using the Bradford method. Proteins $(20 \mu \mathrm{g})$ were size-fractionated using 10\% SDS-PAGE and transferred onto nitrocellulose membranes. The membranes were blocked for $2 \mathrm{~h}$ at room temperature with $5 \%$ non-fat milk and then incubated overnight at $4^{\circ} \mathrm{C}$ with the following primary antibodies: CSE rabbit monoclonal antibody (cat. no. 19689; 1:1,000; Cell Signaling Technology, Inc.), VE-cadherin rabbit polyclonal antibody (cat. no. ab33168; 1:1,000; Abcam), $\alpha$-SMA mouse monoclonal antibody (cat. no. ab7817; 1:1,000; Abcam), IкB $\alpha$ antibody (cat. no. 4814; 1:1,000; Cell Signaling Technology, Inc.), phosphorylated (phospho)-I $\kappa \mathrm{B} \alpha$ (Ser32/36) (5A5) mouse monoclonal antibody (cat. no. 9246; 1:1,000; Cell Signaling Technology, Inc.), Snail rabbit monoclonal antibody (cat. no. 3879; 1:1,000; Cell Signaling Technology, Inc.) and GAPDH rabbit monoclonal antibody (cat. no.ab181602; 1:1,000; Abcam). Membranes were then incubated with secondary antibodies for $2 \mathrm{~h}$ with Dylight ${ }^{\mathrm{TM}} 800$ 4XPEG-conjugated anti-rabbit IgG (H+L) (cat. no. 5151; 1:5,000; Cell Signaling Technology, Inc.) or Dylight ${ }^{\mathrm{TM}}$ 8004XPEG-conjugated anti-mouse IgG (H+L; cat. no. 5257; 1:5,000; Cell Signaling Technology, Inc.) at room temperature. The results were visualized using an Odysse ${ }^{\circledR} \mathrm{Clx}$ Imaging Infrared System and analyzed by ImageJ 1.47 software (National Institutes of Health).

Immunofluorescent staining. Lung sections were deparaffinized in xylene and rehydrated in aqueous solutions with a decreasing alcohol series, followed by washing with PBST (1xPBS with $0.5 \%$ Tween 20; $\mathrm{pH} 7.4$ ). Antigen retrieval was performed by heating the slides in Tris-EDTA solution for $20 \mathrm{~min}$ at $95^{\circ} \mathrm{C}$. Slides were then cooled for $15 \mathrm{~min}$ before washing twice with PBS. Endogenous peroxidase activity and nonspecific staining were blocked by incubation with $3 \% \mathrm{H}_{2} \mathrm{O}_{2}$ for $15 \mathrm{~min}$ and $5 \%$ goat serum (Beyotime Institute of Biotechnology) for $1 \mathrm{~h}$, respectively. Slides were subsequently incubated with VE-cadherin rabbit polyclonal antibody (cat. no. ab33168; Abcam) and $\alpha$-SMA mouse monoclonal antibody (cat. no. ab7817; Abcam) at a 1:100 dilution overnight at $4^{\circ} \mathrm{C}$. For the immunofluorescent staining of HPAECs, cells were rinsed with PBS, fixed with $4 \%$ paraformaldehyde for $20 \mathrm{~min}$ at room temperature and incubated with VE-cadherin rabbit polyclonal antibody (cat. no. ab33168; Abcam; 1:100) and $\alpha$-SMA mouse monoclonal antibody (cat. no. ab7817; Abcam; 1:100) overnight at $4^{\circ} \mathrm{C}$. Slides were washed three times and incubated with Alexa Fluro ${ }^{\circledR} 594$ conjugated anti-rabbit IgG (cat. no. 8889; Cell Signaling Technology, Inc.) and Alexa Fluro ${ }^{\circledR} 488$ conjugated anti-mouse IgG (cat. no. 4408; Cell Signaling Technology, Inc.) for $1 \mathrm{~h}$ at room temperature, at a 1:1,000 dilution. Nuclei were stained using 4,6-diamidino-2-phenylindole (DAPI) for $5 \mathrm{~min}$ at room temperature. Stained cells were observed using light microscopy (Nikon Corporation) and analyzed using NIS-Elements Imaging 4.50 software (Nikon Corporation).

Transcription activity of $N F-\kappa B$. Nuclear extracts from lungs or HPAECs were obtained using a nuclear extraction kit (Active Motif, Inc.). Nuclear protein concentrations were assayed using the Bradford method (Bio-Rad Laboratories, Inc.). The DNA binding activity of NF- $\kappa \mathrm{B}$ p 65 in nuclear extracts was determined, in duplicate, using Trans $\mathrm{AM}^{\mathrm{TM}}$ $\mathrm{NF}-\kappa \mathrm{B}$ p65 Colorimetric kits (Active Motif, Inc.) as according to the protocol described by the manufacturer. The absorbance was read on a 96-well microplate reader (Tecan Group, Ltd.) at $450 \mathrm{~nm}$ with a reference wavelength of $655 \mathrm{~nm}$.

CSE cDNA cloning and transient transfection. The open reading frame of $\mathrm{CSE}$ from the $\mathrm{C} 57 \mathrm{BL} / 6 \mathrm{~J}$ mouse liver (GenBank $^{\mathrm{TM}}$ accession no. NM_145953) was amplified using PCR and then subcloned into the mammalian expression vector pcDNA3.1 (Invitrogen; Thermo Fisher Scientific, Inc.) (16). The CSE expression vectors or control vectors were transiently transfected into HPAECs using FuGENE HD Transfection reagent (Roche Diagnostics). A period of $48 \mathrm{~h}$ after transfection, cells were pretreated with PAG $(2 \mathrm{mM})$ or saline and then stimulated with TGF- $\beta 1(10 \mathrm{ng} / \mathrm{ml})$ for $24 \mathrm{~h}$. A number of cells were harvested to investigate the changes in the NF- $\kappa \mathrm{B}-$ Snail pathway. The remaining cells were subsequently stimulated with TGF- $\beta 1(10 \mathrm{ng} / \mathrm{ml})$ for an additional 9 days to estimate the process of EndMT.

Measurement of plasma $\mathrm{H}_{2} \mathrm{~S}$. Reactions containing $220 \mu \mathrm{l}$ plasma, $60 \mu \mathrm{l} 1 \%$ zinc acetate, $40 \mu \mathrm{l}$, $\mathrm{N}$-dimethyl-p-phenylenediamine sulfate in $7.2 \mathrm{M} \mathrm{HCl}(20 \mu \mathrm{M})$ and $40 \mu \mathrm{FeCl}_{3}$ in $1.2 \mathrm{M} \mathrm{HCl}(30 \mu \mathrm{M})$ were prepared. After $10 \mathrm{~min}$, reactions were terminated by adding $120 \mu \mathrm{l}$ $10 \%$ trichloroacetic acid, which was used to precipitate the proteins. The resulting solution was centrifuged at $14,000 \mathrm{x} \mathrm{g}$ for $5 \mathrm{~min}$ at $4^{\circ} \mathrm{C}$. The absorbance of the final solution was measured at $670 \mathrm{~nm}$ using a 96-well microplate reader (Tecan Group, Ltd.). The plasma concentration of $\mathrm{H}_{2} \mathrm{~S}$ was calculated against a calibration curve of NaHS.

$\mathrm{H}_{2} \mathrm{~S}$ synthesizing activity assay. $\mathrm{H}_{2} \mathrm{~S}$ synthesizing activity in the lungs was measured as previously described (16). The reaction mixture containing $100 \mathrm{mM}$ potassium phosphate buffer (pH 7.4), 20 mM L-cysteine, 2 mM pyridoxyal 5'-phosphate and tissue homogenate, was prepared in tightly sealed tubes on ice. Tubes were subsequently transferred to a water bath at $37^{\circ} \mathrm{C}$ to initiate the reactions. After $30 \mathrm{~min}, 1 \%$ zinc acetate was added to entrap synthesized $\mathrm{H}_{2} \mathrm{~S}$ and $10 \%$ trichloroacetic acid was subsequently added to stop the reaction. Additionally, $20 \mu \mathrm{M}$ $\mathrm{N}, \mathrm{N}$-dimethyl-p-phenylenediamine sulfate in $7.2 \mathrm{M} \mathrm{HCl}$ was added, followed by $30 \mu \mathrm{M} \mathrm{FeCl}_{3}$ in $1.2 \mathrm{M} \mathrm{HCl}$. The absorbance of the final solution was determined at $670 \mathrm{~nm}$ using 
spectrophotometry (TecanGroup, Ltd.). The concentration of $\mathrm{H}_{2} \mathrm{~S}$ in each reaction mixture was calculated against a calibration curve of $\mathrm{NaHS}_{2} \mathrm{H}_{2} \mathrm{~S}$ synthesizing activity in the lungs was expressed as $\mathrm{nmol}_{2} \mathrm{~S}$ formed/mg DNA after being adjusted to the DNA concentration in lung homogenates.

Statistical analysis. Data are expressed as the mean \pm standard error of the mean. Statistical analysis was performed using SPSS software 19 (IBM Corp.). Significant differences were determined using a two-tailed Student's $t$ test or using one-way analysis ovariance with a Tukey's multiple comparison test. $\mathrm{P}<0.05$ was considered to indicate a statistically significant result. Each experiment was repeated a minimum of three times.

\section{Results}

Time-dependent alterations of EndMT in MCT-induced $P A H$. To assess the time-dependent alterations of EndMT in MCT-induced PAH, pulmonary protein levels of VE-cadherin (an endothelial marker), $\alpha$-SMA (a mesenchymal marker) and Snail were measured, as crucial regulators of EndMT $(18,19)$. As presented in Fig. 1A and B, VE-cadherin expression time-dependently reduced during the development of PAH, with a considerable decrease 21 days after MCT injection. In contrast, $\alpha$-SMA expression was significantly upregulated at 14 days after MCT injection $(\mathrm{P}<0.05)$ and remained highly expressed throughout the experiment. Furthermore, the pulmonary expression of Snail was increased following MCT injection, with a peak 21 days after the initial MCT injection. The results also indicated that the plasma concentration of $\mathrm{H}_{2} \mathrm{~S}$, lung $\mathrm{H}_{2} \mathrm{~S}$ synthesizing activity and lung CSE expression significantly reduced 14 days after MCT injection and remained at a decreased level $(\mathrm{P}<0.05$; Fig. 1C-E). The time course experiments demonstrated that an insufficiency of endogenous $\mathrm{H}_{2} \mathrm{~S}$ production in lungs accompanied the process of EndMT in MCT-induced PAH, with a peak alteration 21 days after MCT injection.

Effect of $\mathrm{H}_{2} \mathrm{~S}$ on EndMT in MCT-induced PAH. A period of 7 days after MCT injection, rats randomly received a daily administration of NaHS $\left(1 \mathrm{mg} / \mathrm{kg}\right.$ ), PAG (an inhibitor of $\mathrm{H}_{2} \mathrm{~S}$ synthesis; $10 \mathrm{mg} / \mathrm{kg}$ ) or saline. A period of 3 weeks after MCT injection, pulmonary hemodynamic, right ventricular hypertrophy and pulmonary structural changes were assessed (Fig. 2). Hemodynamic and echocardiographic measurements demonstrated that a preventive application of NaHS significantly reduced PAH responses (pulmonary arterial systolic and mean pressures), right ventricular hypertrophy $(\mathrm{RV} / \mathrm{LV}+\mathrm{S})$ and right ventricular systolic function, while inhibition of $\mathrm{H}_{2} \mathrm{~S}$ formation by PAG aggravated them (Fig. 2A-D). Furthermore, NaHS significantly alleviated pulmonary vascular structural remodeling, as characterized by a reduced thickness of the medial layer of muscular arteries (vessels of $\sim 150 \mu \mathrm{m}$ diameter) and decreased narrowness in muscular arteries, whereas PAG aggravated the severity of PAH ( $\mathrm{P}<0.05$; Fig. 2E and 2F). Additionally, the therapeutic effect of NaHS was examined via administration 14 days after MCT injection. Unfortunately, the therapeutic administration of NaHS was unable to mitigate the severity of PAH (data not shown).
Subsequently, whether NaHS exhibited an effect on pulmonary EndMT in MCT-induced PAH was assessed. As presented in Fig. 3A, NaHS significantly upregulated the expression of VE-cadherin and reduced the expression of $\alpha$-SMA in the lungs, suggesting a partial reversion of pulmonary EndMT $(\mathrm{P}<0.05)$. An additional loss of VE-cadherin and an additional gain of $\alpha$-SMA were observed in the lungs of PAH rats treated with PAG. To further determine whether NaHS affected EndMT in pulmonary ECs, double immunofluorescent staining was used for VE-cadherin and $\alpha$-SMA in the lung tissue sections (Fig. 3B). Red-stained VE-cadherin positive ECs were detected in the lung tissue of control rats, or in PAH rats treated with NaHS, whereas green-stained $\alpha$-SMA positive ECs were identified in small numbers. However, PAH rats that were administered PAG indicated decreased expression of VE-cadherin and increased expression of $\alpha$-SMA when compared with PAH rats administered saline.

In accordance with the protein pattern, electron microscopy observations revealed that NaHS affected the ultrastructural characteristics of EndMT in MCT-induced PAH. As presented in Fig. 3C, ECs were flat, elongated and characterized by a high density of caveolae and Weibel-Palade bodies (WPB) in the control pulmonary arteries. In MCT-induced rats, luminal pulmonary ECs revealed a mixed ultrastructural phenotype, as characterized by possessing high-density caveolae and WPBs, exhibiting detectable microfilaments and ongoing cell migration/invagination directed toward the intima. In conclusion, NaHS treatment restored the ultrastructural alterations of EndMT induced by MCT, while PAG aggravated it (Fig. 3C).

Effect of $\mathrm{H}_{2} \mathrm{~S}$ on $\mathrm{NF}-\kappa \mathrm{B}$-Snail signaling pathway in $M C T$-induced PAH. The activation of the NF- $\kappa \mathrm{B}-$ Snail signaling pathway is known to be required for the EndMT (18-20). Therefore, the role of $\mathrm{H}_{2} \mathrm{~S}$ in regulating the NF-kB-Snail pathway in MCT-induced EndMT was assessed. The results revealed that treatment with NaHS inhibited the activation of NF- $\mathrm{KB}$ and the subsequent transcription of Snail, and this was demonstrated by a decreased level of

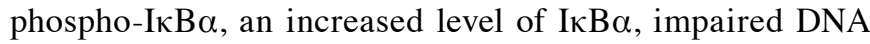
binding activity of $\mathrm{p} 65$ and the consequent downregulation of Snail expression (Fig. 4A and B). However, the inhibition of $\mathrm{H}_{2} \mathrm{~S}$ synthesis, by PGA, affected the NF- $\kappa \mathrm{B}-$ Snail signaling pathway in the opposite manner (Fig. 4A and B).

Effect of $\mathrm{H}_{2} \mathrm{~S}$ on TGF- $\beta 1$-induced EndMT in HPAECs. To further investigate the role of $\mathrm{H}_{2} \mathrm{~S}$ in endothelial cell EndMT, TGF- $\beta 1(10 \mathrm{ng} / \mathrm{ml})$ was used to stimulate HPAECs. The results of western blot analysis and double immunofluorescent staining indicated that TGF- $\beta 1$ stimulation induced the upregulation of $\alpha$-SMA expression with a concomitant downregulation of VE-cadherin in HPAECs (Fig. 5A and B). Treatment with NaHS significantly inhibited TGF- $\beta 1$ induced EndMT, as demonstrated by a dose-dependent decrease in $\alpha$-SMA expression and a dose-dependent increase in VE-cadherin (Fig. 5A). A similar pattern was indicated using immunofluorescent staining (Fig. 5B). Furthermore, TEM was used to investigate the ultrastructural alterations of HPAECs. After exposure to TGF- $\beta 1$ for 10 days, HPAECs presented a mixed ultrastructural phenotype, exhibiting the features of ECs (caveolae and WPBs) and the characteristics of SMC (microfilaments; 
A

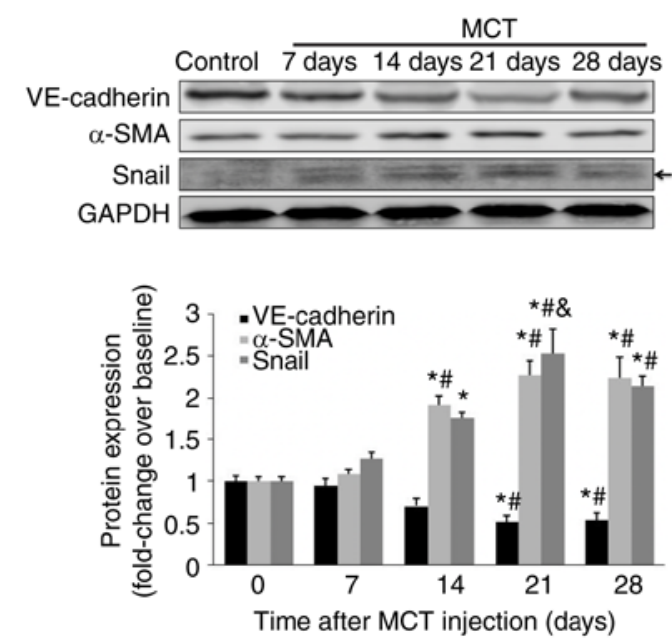

C
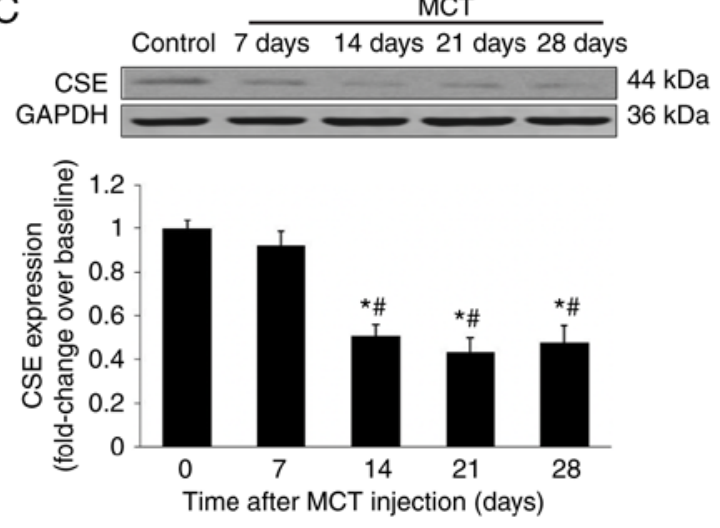
$120 \mathrm{kDa}$
$42 \mathrm{kDa}$
$29 \mathrm{kDa}$
$36 \mathrm{kDa}$

B Time after MCT injection VE-cadherin
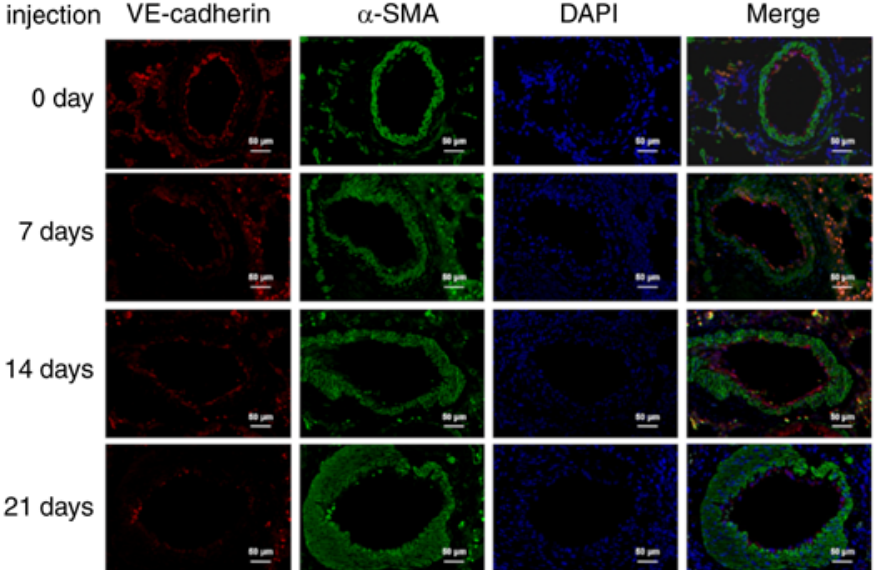

21 days
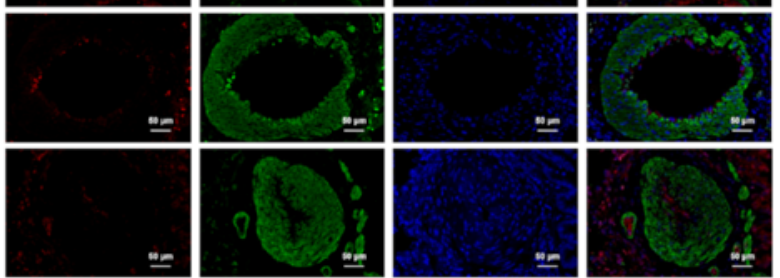

28 days
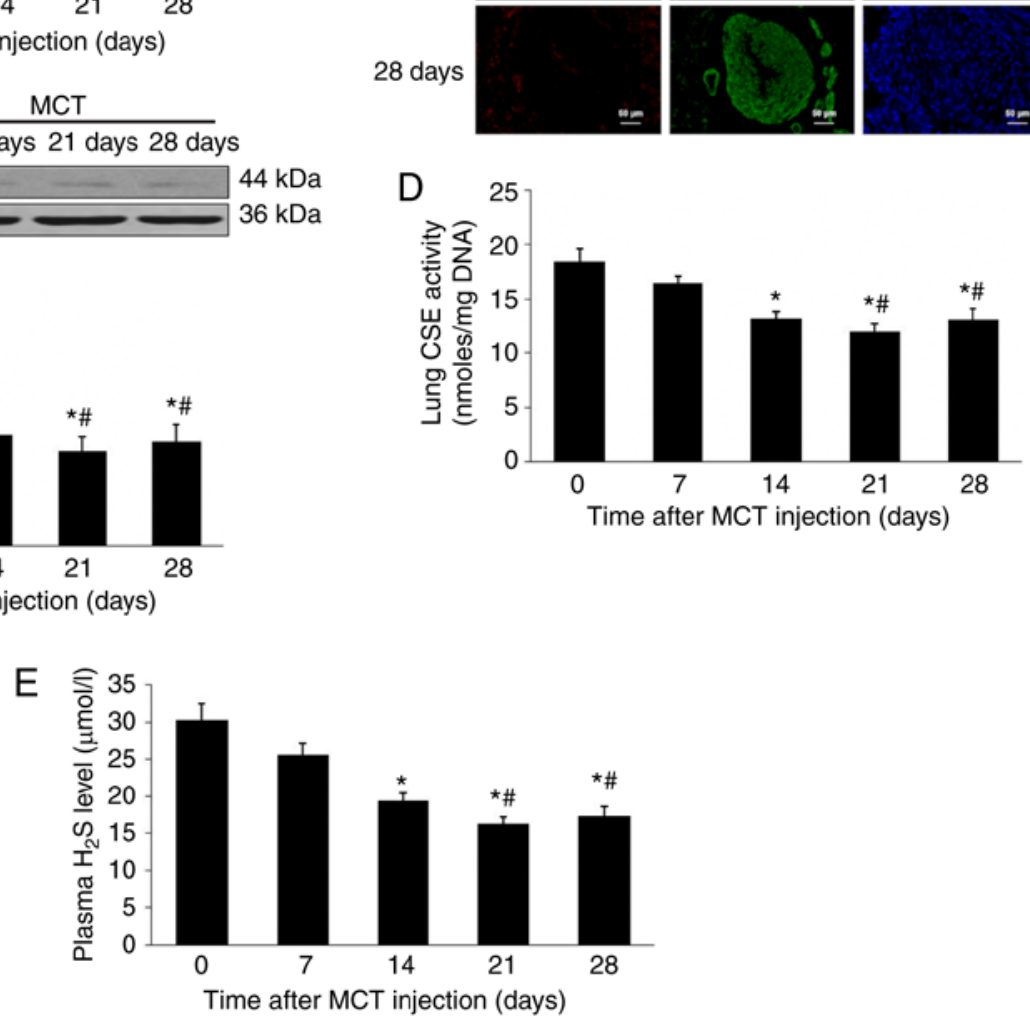

Figure 1. Time dependent alterations in protein signatures of EndMT and the dynamic characteristics of endogenous $\mathrm{H}_{2} \mathrm{~S}$ synthesis in $\mathrm{MCT}$-induced PAH After injection with MCT, rats were sacrificed at days 0, 7, 14, 21 and 28. Temporal characteristics of VE-cadherin and $\alpha$-SMA in lungs were measured using (A) western blot analysis and (B) immunofluorescent staining. Red fluorescence represents VE-cadherin, green fluorescence represents $\alpha$-SMA and blue fluorescence indicates DAPI nuclei staining. Expression of (A) Snail and (C) CSE in the lungs was measured using western blot analysis. (D) Lung CSE enzymatic activity and (E) plasma $\mathrm{H}_{2} \mathrm{~S}$ level were also measured. Results are presented as the mean \pm standard error of the mean ( $\mathrm{n}=6$ animals in each group). ${ }^{*} \mathrm{P}<0.05$ vs. rats at baseline; ${ }^{*} \mathrm{P}<0.05$ vs. rats 7 days after MCT injection; ${ }^{\circledR} \mathrm{P}<0.05$ vs. rats 14 days after MCT injection. EndMT, endothelial-to-mesenchymal transition; $\mathrm{H}_{2} \mathrm{~S}$, hydrogen sulfide; MCT, monocrotaline; PAH, pulmonary arterial hypertension; CSE, cystathionine $\gamma$-lyase; SMA, smooth muscle actin; VE, vascular endothelial; DAPI, 4,6-diamidino-2-phenylindole.

Fig. 5C). Treatment with NaHS, at a dose of $100 \mu \mathrm{M}$, partially reversed the ultrastructural phenotypic shift in HPAECs that were induced by TGF- $\beta 1$ (Fig. 5C). Consistent with this was the alteration in cell morphology. HPAECs changed from a cobblestone appearance into an elongated, spindle shape when stimulated with TGF- $\beta 1$ for 10 days (Fig. 5D). Treatment with NaHS partially reversed the TGF- $\beta 1$-induced morphological change (Fig. 5D). Ultrastructural and morphology observations further supported the potential role of $\mathrm{H}_{2} \mathrm{~S}$ in the process of EndMT. Additionally, the impact of NaHS on the NF- $\mathrm{kB}-$ Snail pathway was examined. In agreement with the aforementioned results, NaHS dose-dependently inhibited the activation of NF- $\mathrm{KB}$ and subsequent transcription of Snail in TGF- $\beta 1$-stimulated HPAECs (Fig. 5E and F).

Effect of CSE overexpression on EndMT in TGF- $\beta 1$ stimulated HPAECs. HPAECs were transfected with a CSE plasmid to mimic the supplementation of $\mathrm{H}_{2} \mathrm{~S}$ (Fig. S1). In accordance with the findings demonstrated in the NaHS treatment, the overexpression of CSE considerably inhibited TGF- $\beta 1$ induced EndMT. Western blot analysis and immunofluorescent staining indicated that significantly upregulated $\alpha$-SMA expression 
A

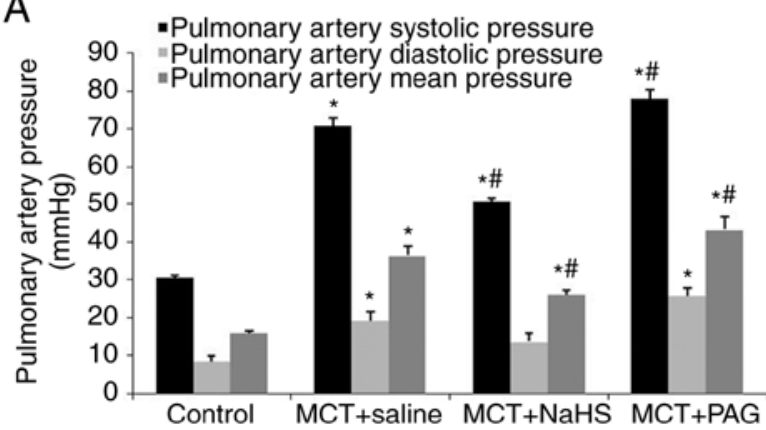

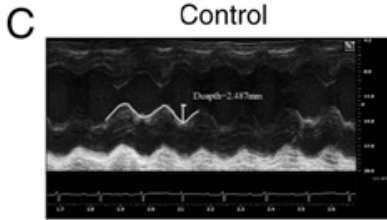

$\mathrm{MCT}+\mathrm{NaHS}$

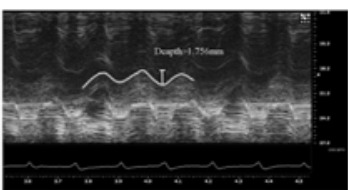

E

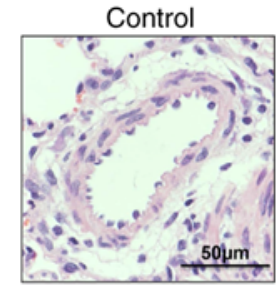

$\mathrm{MCT}+\mathrm{NaHS}$

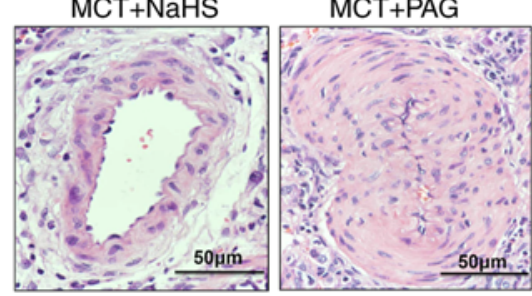

MCT+saline

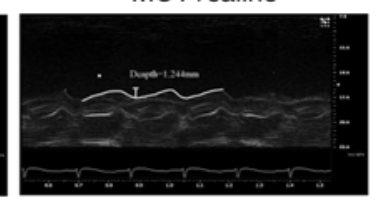

$\mathrm{MCT}+\mathrm{PAG}$

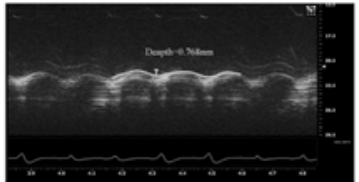

MCT+saline

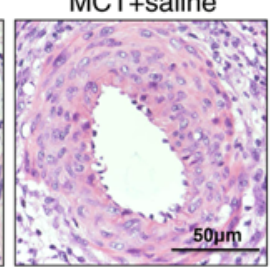

$\mathrm{MCT}+\mathrm{PAG}$

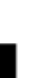

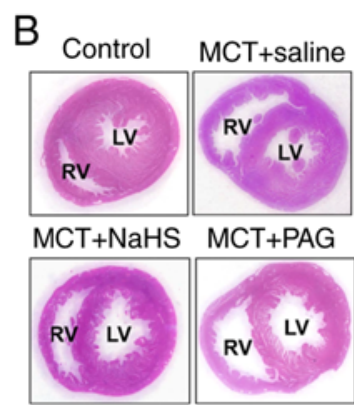
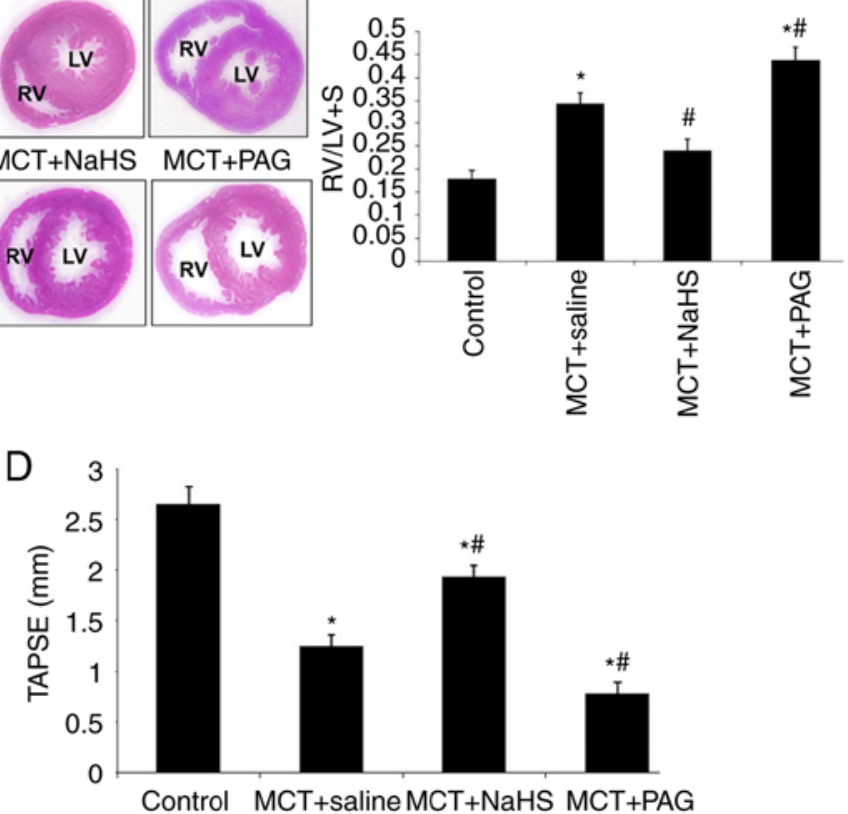

$\mathrm{F}$

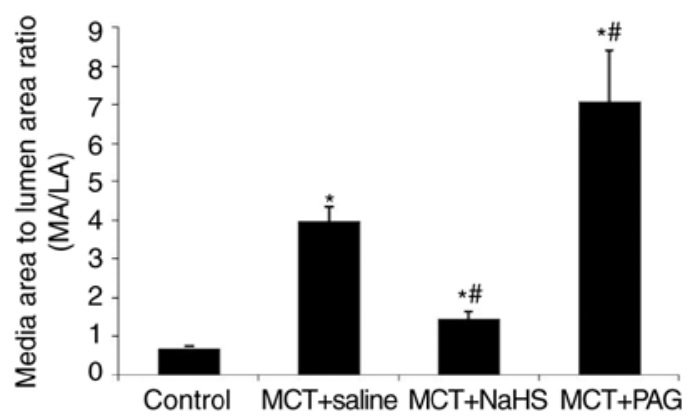

Figure 2. Effect of supplementation with exogenous $\mathrm{H}_{2} \mathrm{~S}$ (NaHS) or inhibition of $\mathrm{H}_{2} \mathrm{~S}$ formation by PAG on MCT-induced PAH. Rats received NaHS (i.p., $1 \mathrm{mg} / \mathrm{kg} /$ day) or PAG (i.p, $10 \mathrm{mg} / \mathrm{kg} /$ day) 7 days after MCT injection. A period of 21 days after injection of MCT, rats were anesthetized and underwent RHC. (A) Pulmonary artery systolic pressure, pulmonary arterial diastolic pressure and pulmonary arterial mean pressure were continuously recorded. (B) The RV/(LV+S) ratio was calculated, as described in materials and methods, to estimate RV hypertrophy. (C) Right ventricular ejection fraction was indicated by TAPSE measured using ultrasound and (D) quantitative analysis. (E) Pulmonary vascular remodeling was assessed using hematoxylin and eosin staining. (F) Media to lumen ratio (MA/LA) was measured as described in the materials and methods, to evaluate the remodeling of pulmonary arteries. The results are presented as the mean \pm standard error of the mean ( $\mathrm{n}=6$ animals in each group). ${ }^{*} \mathrm{P}<0.05$ vs. the control group; ${ }^{\#} \mathrm{P}<0.05$ vs. rats with $\mathrm{MCT}+\mathrm{saline}$. $\mathrm{H}_{2} \mathrm{~S}$, hydrogen sulfide; PAG, DL-propagylglycine; PAH, pulmonary arterial hypertension; RV/(LV+S), weight ratio of the right ventricle to left ventricle plus septum; MCT, monocrotaline. TAPSE, tricuspid annular plane systolic excursion. MA, media area; LA, lumen area; i.p., intraperitoneal.

and suppressed VE-cadherin expression, which was caused by TGF- $\beta 1$, were significantly reversed by CSE overexpression $(\mathrm{P}<0.05$; Fig. 6A and B). An examination of the ultrastructure also revealed that CSE overexpression was associated with the repression of the endothelial phenotype shift (Fig. 6C). Furthermore, CSE overexpression resulted in an obvious reduction in the TGF- $\beta 1$-induced transactivation of NF- $\kappa \mathrm{B}$ and transcription of Snail (Fig. 6D and E). However, the inhibitory effect of CSE overexpression on TGF- $\beta$-induced EndMT and the activation of NF- $\kappa$ B-Snail pathway, was abrogated by pretreatment with PAG (Fig. 6). In conclusion, CSE overexpression was unable to alter EndMT, cell morphology and ultrastructure in TGF- $\beta 1$-stimulated HPAECs when cells were pretreated with PAG.

\section{Discussion}

Epithelial to mesenchymal transition (EMT) is defined as a phenotypic switch from an epithelial to mesenchymal cell, which serves important roles in embryonic development and a variety of adult conditions, including fibrosis, wound repair, inflammation and malignancy (2). The endothelium is a specialized form of squamous epithelial tissue and as such, EndMT is a subcategory of EMT. EndMT has previously been recognized as a new paradigm in PAH pathobiology (5-7). Although the protective effect of $\mathrm{H}_{2} \mathrm{~S}$ in PAH has been well established, its role in EndMT has not yet been determined. In the present study, the results demonstrated that EndMT is 
A
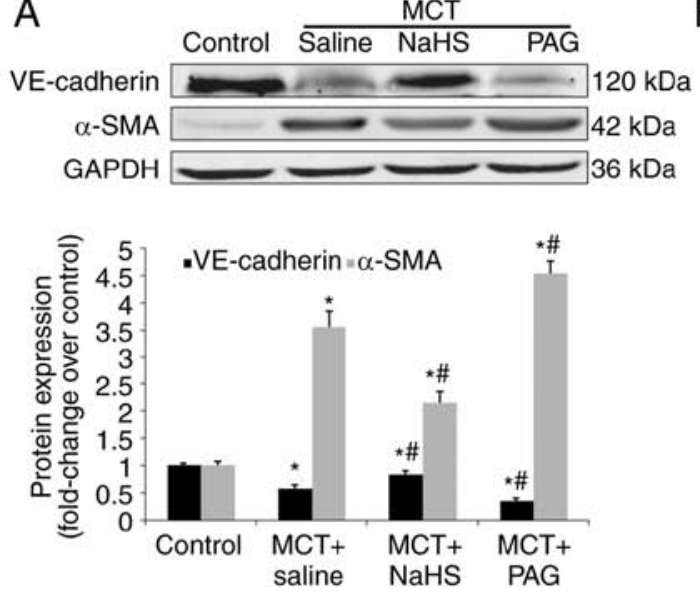

B
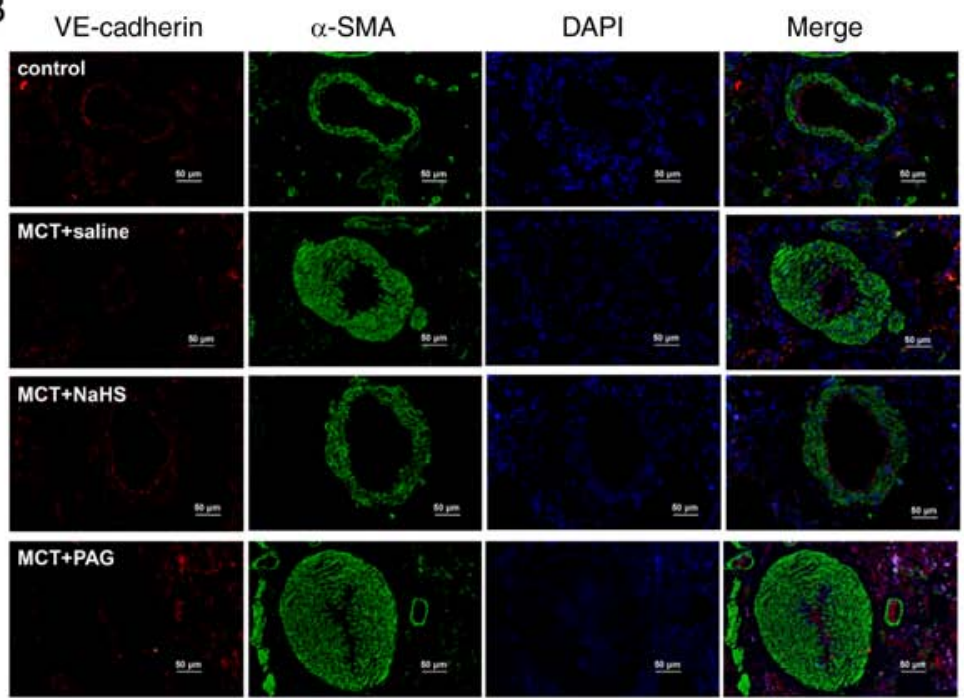

C
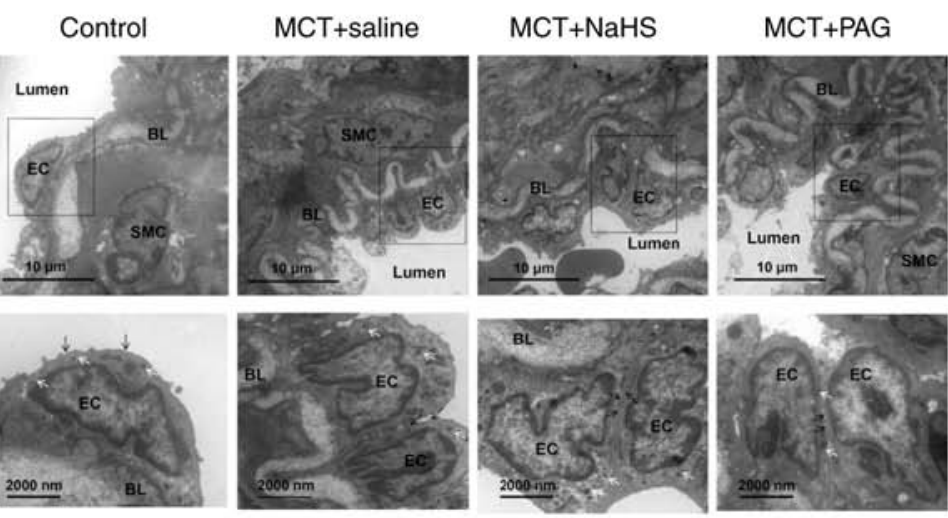

Figure 3. Effect of NaHS or PAG on EndMT in MCT-induced PAH. Rats received NaHS (i.p., 1 mg/kg/day) or PAG (i.p, 10 mg/kg/day) 7 days after MCT injection. A period of 21 days after injection of MCT, rats were sacrificed ( $n=6$ animals in each group). The pulmonary expression levels of EndMT markers, VE-cadherin and $\alpha$-SMA were examined using (A) western blot analysis and (B) immunofluorescent staining. Red fluorescence represents VE-cadherin, green fluorescence represents $\alpha$-SMA and blue fluorescence represents 4,6-diamidino-2-phenylindole nuclei staining. (C) The ultrastructure of the pulmonary artery was assessed using transmission electron microscopy. In the control group, endothelial cells are flat, elongated and separated from smooth muscle cells via a thick basement membrane, the BL. In the MCT group, endothelial cells display migration in the intima and alter their nuclei orientation. Endothelial characteristics of these cells are confirmed by the presence of caveolae (black arrow) and Weibel-Palade bodies (white arrows). ${ }^{*} \mathrm{P}<0.05$ vs. the control group; ${ }^{\#} \mathrm{P}<0.05$ vs. rats with MCT+saline. NaHS, exogenous $\mathrm{H}_{2} \mathrm{~S}$; PAG, DL-propagylglycine; PAH, pulmonary arterial hypertension; EndMT, endothelial-to-mesenchymal transition; MCT, monocrotaline; EC, endothelial cells; SMC, smooth muscle cells; BL, basal lamina; i.p., intraperitoneal; SMA, smooth muscle actin; VE, vascular endothelial.

accompanied by an endogenous deficiency of $\mathrm{H}_{2} \mathrm{~S}$ in $\mathrm{PAH}$. The administration of exogenous $\mathrm{H}_{2} \mathrm{~S}$ was indicated to prevent MCT-induced PAH. The protective mechanism governing this is likely to be associated with the reversal of the EndMT process by inhibiting NF- $\kappa \mathrm{B}-$ Snail axis molecules.

In the current study, a time-dependent feature of the endothelial phenotype shift was identified in MCT-induced PAH. The expression of $\alpha$-SMA, a mesenchymal marker, was increased 14 days after MCT injection, while the expression of VE-cadherin, an endothelial differentiation marker, was inhibited. EndMT continued until 28 days after MCT injection. These findings are supported by the temporal trend of EndMT obtained by a study performed by Ranchoux et al (7), which identified the overexpression of mesenchymal markers, Twist-1, vimentin and P-vimentin, were associated with a strong repression of VE-cadherin and p120-catenin protein expression. This aforementioned study also observed pulmonary luminal cells displaying a mixed phenotype endothelial/mesenchymal cells at 21 and 28 days after MCT injection (7). Furthermore, Nikitopoulou et al (21) reported that injection of rats with MCT produced a significant decline of VE-cadherin at $24 \mathrm{~h}$ and 15 days, with recovery observed at 28 days. The current study also indicated a slight rebound in the expression of VE-cadherin and Snail 28 days after MCT injection. This may be due to vascular remodeling by transformed endothelial cells responding to angiogenic and proliferative stimuli at the late stage of $\mathrm{PAH}$ rather than a true recovery. Conversely, CSE expression in lungs was revealed to be significantly downregulated 14 days after MCT injection. CSE activity in the lungs and the plasma level of $\mathrm{H}_{2} \mathrm{~S}$, consequently dropped and remained at a low level. The temporal observations in EndMT and $\mathrm{H}_{2} \mathrm{~S}$ biosynthesis suggested that MCT triggered the process of EndMT and inhibited the synthesis of endogenous $\mathrm{H}_{2} \mathrm{~S}$.

In an attempt to further determine the association between $\mathrm{H}_{2} \mathrm{~S}$ and EndMT, an exogenous $\mathrm{H}_{2} \mathrm{~S}$ donor, NaHS, was used. 

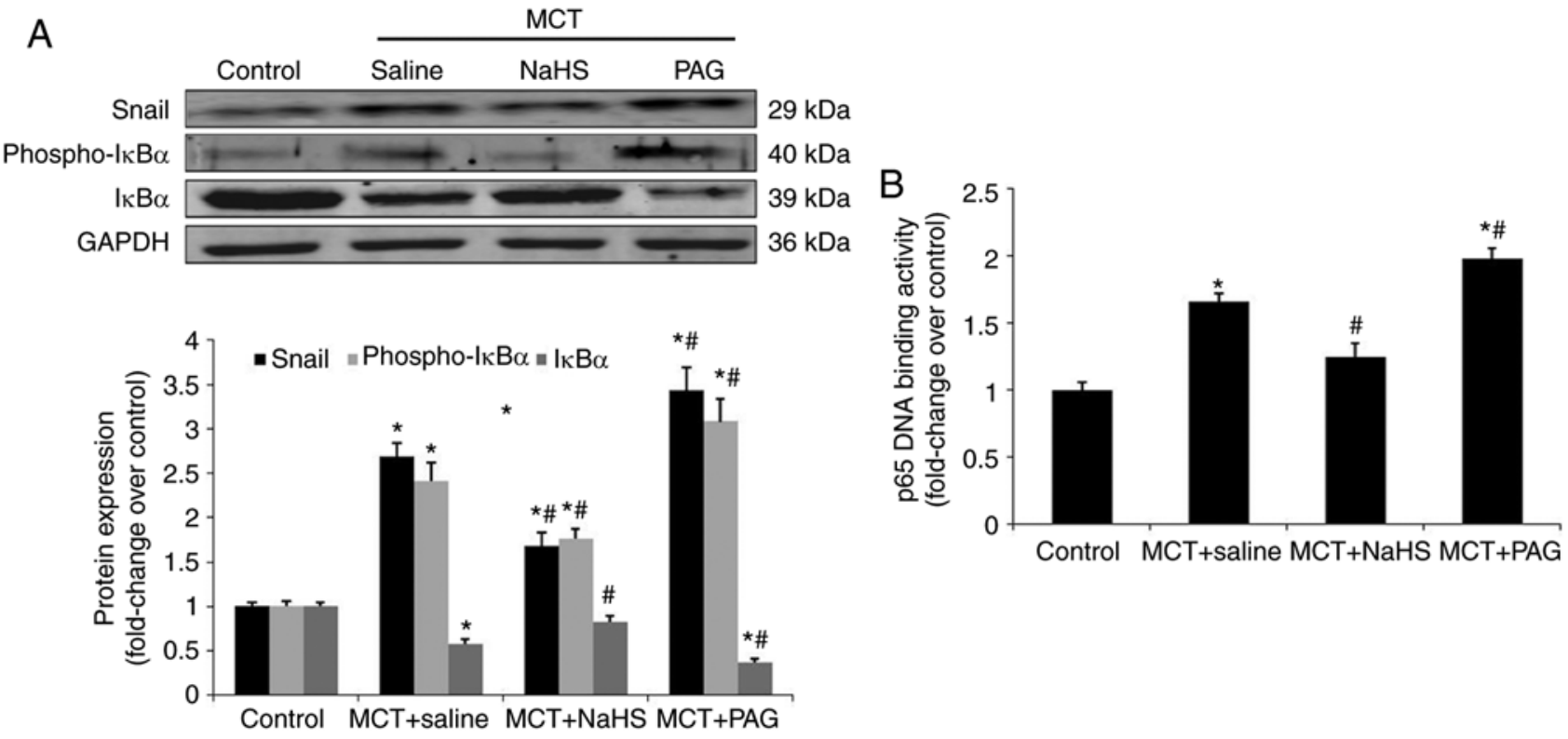

Figure 4. Effect of NaHS or PAG on NF-kB-Snail pathway in MCT-induced PAH. Rats received NaHS (i.p., $1 \mathrm{mg} / \mathrm{kg} / \mathrm{day}$ ) or PAG (i.p, $10 \mathrm{mg} / \mathrm{kg} / \mathrm{day}) 7 \mathrm{days}$ after MCT injection. A period of 21 days after injection of MCT, rats were sacrificed. Pulmonary expression of Snail, phospho-IкB $\alpha$ and IкB $\alpha$ were measured using (A) western blot analysis. (B) p65 DNA binding activity in lung nuclear extracts were measured as described in the materials and methods. The results are presented as the mean \pm standard error of the mean ( $\mathrm{n}=6$ animals in each group). ${ }^{*} \mathrm{P}<0.05$ vs. the control group; ${ }^{\mathrm{P}} \mathrm{P}<0.05$ vs. rats with $\mathrm{MCT}+$ saline. NaHS exogenous $\mathrm{H}_{2} \mathrm{~S}$; PAG, DL-propagylglycine; PAH, pulmonary arterial hypertension; MCT, monocrotaline; phospho, phosphorylated; i.p., intraperitoneal; NF, nuclear factor.

NaHS treatment reversed the process of EndMT and alleviated the severity of PAH. Using western blot analysis and double immunofluorescent staining, the results demonstrated that the decrease of endothelial cadherin and the increase of $\alpha$-SMA were partially ameliorated by NaHS. The ultrastructure characteristics of EndMT, which were evaluated by TEM supported these previous findings. In contrast, abolishing systemic $\mathrm{H}_{2} \mathrm{~S}$ by PAG promoted the endothelial phenotype shift and aggravated PAH and pulmonary vascular remodeling. These results support the assumption that $\mathrm{H}_{2} \mathrm{~S}$ is important in the development and progression of EndMT in MCT-induced PAH.

It is known that the TGF- $\beta$ signaling pathway plays important roles in the onset or development of MCT-induced PAH (22-24). TGF- $\beta 1$ induces pulmonary endothelial cells to undergo EndMT (25). Then, the effect of $\mathrm{H}_{2} \mathrm{~S}$ on EndMT in TGF- $\beta 1$ stimulated HPAECs was investigated. Cultured HPAECs with TGF- $\beta 1$ for 10 days resulted in EndMT, as characterized by a decrease of VE-cadherin and an increase of $\alpha$-SMA, with the typical ultrastructure feature, elongated and spindle-like appearance with microfilamentation in the cytoplasm. Supplementation with exogenous $\mathrm{H}_{2} \mathrm{~S}$ by NaHS or transfection with CSE plasmid significantly reversed this phenotype shift and these results are supported by findings in the MCT rat model. Collectively, the in vivo and in vitro findings of the current study supported the novel concept that EndMT is regulated by $\mathrm{H}_{2} \mathrm{~S}$ in PAH.

As $\mathrm{H}_{2} \mathrm{~S}$ exhibits anti-fibrotic potential in the pathogenesis of pulmonary, renal and hepatic fibrosis, in which EMT participates, the effect of $\mathrm{H}_{2} \mathrm{~S}$ on EMT was initially investigated (26-28). $\mathrm{H}_{2} \mathrm{~S}$ has been indicated to attenuate TGF- $\beta 1$-induced EMT in human alveolar epithelial cells and renal tubular epithelial cells $(27,29,30) . \mathrm{H}_{2} \mathrm{~S}$ has also been revealed to inhibit EMT in human breast cancer cells and hepatocarcinoma cells, and exhibits an anti-cancer action $(31,32)$. Recently, one study investigated the role of $\mathrm{H}_{2} \mathrm{~S}$ in EndMT and demonstrated that $\mathrm{H}_{2} \mathrm{~S}$ protected against endoplasmic reticulum stress-induced EndMT via the Src pathway in human umbilical vein ECs (33). Together with the findings obtained in the present study, these results support the import role of $\mathrm{H}_{2} \mathrm{~S}$ in suppressing the epithelial/endothelial phenotype shift, by which $\mathrm{H}_{2} \mathrm{~S}$ exhibits an anti-fibrotic, anti-oncogenic and anti-PAH effect in a variety of conditions.

Snail is a family of transcription factors that repress the expression of VE-cadherin to promote EMT/EndMT (19). Snail is known to be transcriptionally regulated by NF- $\kappa \mathrm{B}(19,20)$. Therefore, the expression of signal proteins associated with the NF- $\mathrm{KB}$-Snail axis was measured in the present study to investigate the detailed mechanisms underlying the inhibitory effect of $\mathrm{H}_{2} \mathrm{~S}$ on EndMT. The time-course study indicated early augmentation of Snail expression 7 days after MCT injection with a peak on day 21 and the maintenance of high expression on day 28. The temporal pattern of Snail expression is coincident with the chronological shift in endogenous $\mathrm{H}_{2} \mathrm{~S}$ synthesis in MCT-induced PAH, suggesting the possible association between $\mathrm{H}_{2} \mathrm{~S}$ and Snail. The addition of NaHS downregulated the activation of NF- $\mathrm{\kappa B}$, as characterized by the decreased phosphorylation of I $\mathrm{I} B \alpha$, reduced degradation of I $\mathrm{B} \alpha$ and decreased DNA binding activity, leading to the repressed transcription of Snail. However, the eradication of endogenous $\mathrm{H}_{2} \mathrm{~S}$ by PAG stimulated the transactivation of NF- $\kappa \mathrm{B}$ and the expression of Snail. Exogenous $\mathrm{H}_{2} \mathrm{~S}$ or the overexpression of CSE suppressed the activation of NF- $\mathrm{KB}$ and the expression of downstream Snail induced by TGF- $\beta 1$ in HPAECs. From these results, it can be assumed that $\mathrm{H}_{2} \mathrm{~S}$ induced NF- $\mathrm{KB}$ inactivation and consequently caused the transcriptional inhibition of Snail, resulting in the reversal of EndMT. The underlying mechanism 

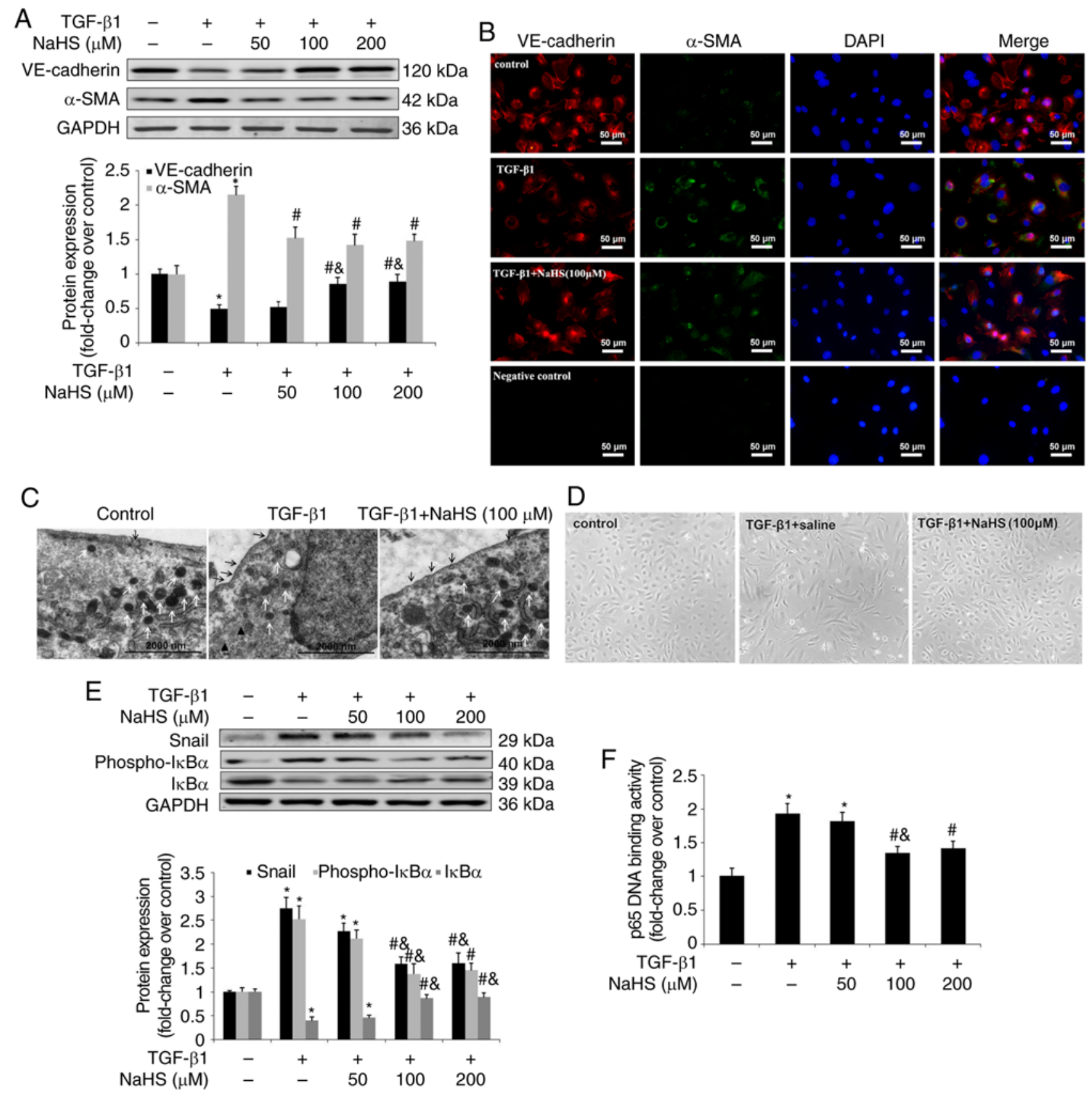

Figure 5. Effect of NaHS on TGF- $\beta 1$-induced EndMT in HPAECs. HPAECs were pre-incubated with saline or NaHS (50, 100 and $200 \mu \mathrm{M})$ for $2 \mathrm{~h}$ and stimulated with TGF- $\beta 1(10 \mathrm{ng} / \mathrm{ml})$ for $24 \mathrm{~h}$ in the continuous presence of NaHS $(50,100$ and $200 \mu \mathrm{M})$ or saline. Some cells were harvested to investigate the changes in NF-KB-Snail pathway. Remaining cells were subsequently stimulated with TGF- $\beta 1(10 \mathrm{ng} / \mathrm{ml})$ for an additional 9 days in an attempt to estimate the process of EndMT. Expression of EndMT markers, VE-cadherin and $\alpha$-SMA was examined using (A) western blot analysis and (B) immunofluorescent staining. Red fluorescence represents VE-cadherin, green fluorescence represents $\alpha$-SMA and blue fluorescence represents DAPI nuclei staining. The ultrastructure of HPAECs was assessed using (C) TEM. Black arrows indicate caveolae. White arrows indicate WPB. Black triangles indicate microfilaments in the cytoplasm. Effect of NaHS on cell morphology in TGF- $\beta 1$-induced EndMT in HPAECs was investigated using (D) phase-contrast light microscopy. Normal HPAECs exhibit a cobblestone appearance and indicate caveolae and WPB, with few microfilaments. Following exposure to TGF- $\beta 1$, microfilamentation appeared in the

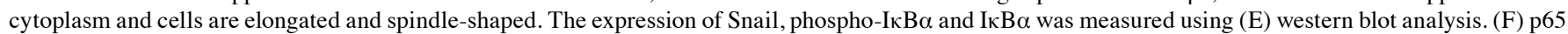
DNA binding activity in nuclear extracts was measured as described in the materials and methods. The data are presented as the mean \pm standard error of the mean of at least three independent experiments. ${ }^{*} \mathrm{P}<0.05$ vs. the control group at baseline; ${ }^{\#} \mathrm{P}<0.05$ vs. TGF- $\beta 1$-stimulated HPAECs treated with saline; ${ }^{\circledR} \mathrm{P}<0.05$ vs. TGF- $\beta 1$-stimulated HPAECs treated with NaHS at a concentration of $50 \mu \mathrm{M}$. NaHS, exogenous $\mathrm{H}_{2} \mathrm{~S}$; EndMT, endothelial-to-mesenchymal transition; HPAEC, human pulmonary artery endothelial cells; WPB, Weibel-Palade bodies; TEM, transmission electron microscopy; VE, vascular endothelial; TGF, transforming growth factor; DAPI, 4,6-diamidino-2-phenylindole.

by which $\mathrm{H}_{2} \mathrm{~S}$ modulates the activity of the NF- $\mathrm{BB}$-Snail signaling pathway remains undetermined. Recently, it has been recognized that $\mathrm{H}_{2} \mathrm{~S}$ functions via a variety of signaling pathways through S-sulfhydration (34). A number of proteins, including transcription factors, could be modified by $\mathrm{H}_{2} \mathrm{~S}$ via
S-sulfhydration and change their original function, serving as important switches or regulators (34). Therefore, future studies should assess whether $\mathrm{H}_{2} \mathrm{~S}$ regulates the epithelial/endothelial phenotypic transition by sulfhydrating NF-kB, or via Snail molecules at their cysteine residues. 


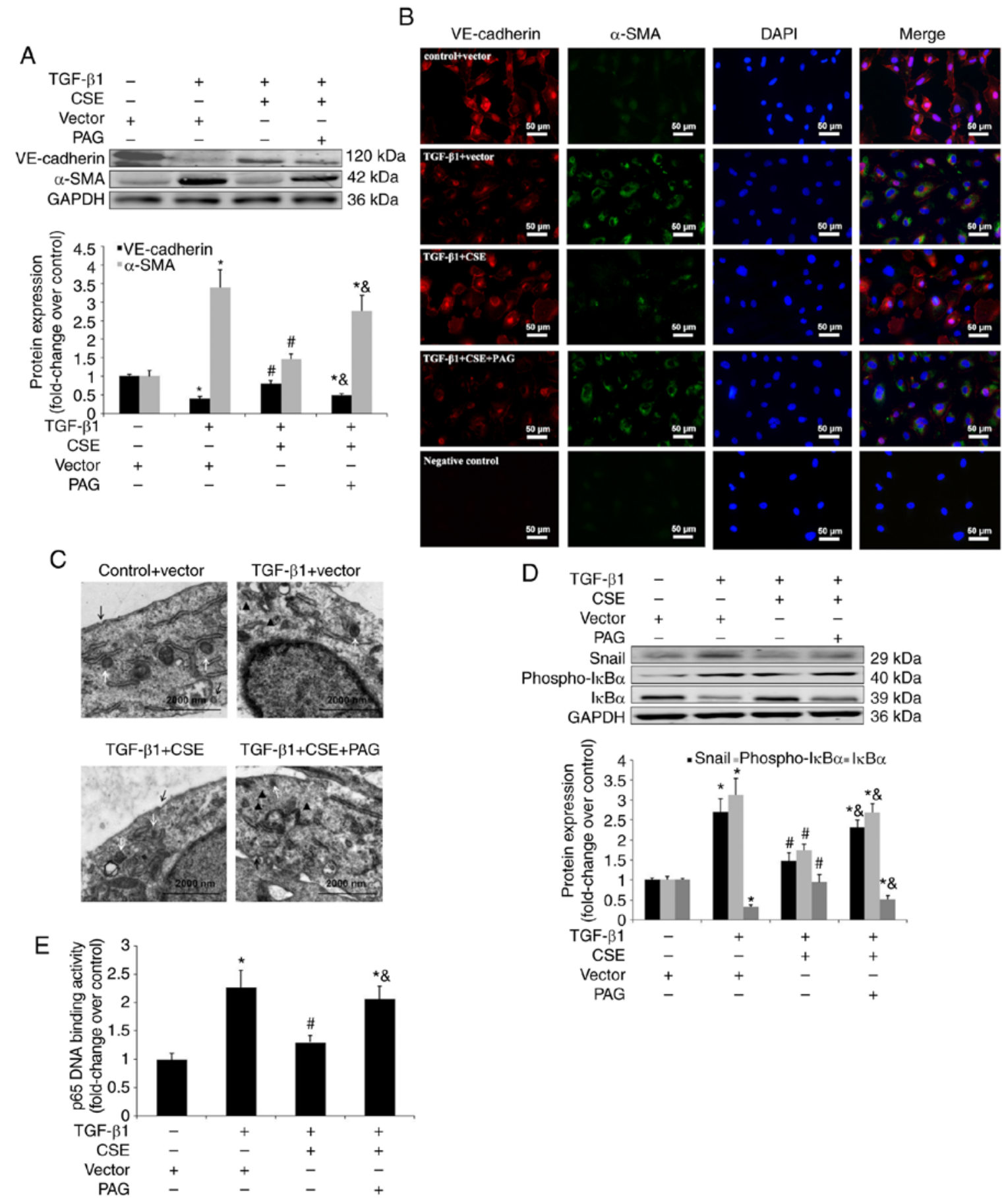

Figure 6. Effect of CSE overexpression on TGF- $\beta 1$-induced EndMT in HPAECs. HPAECs were transfected with a vector or CSE plasmid and stimulated with TGF- $\beta 1(10 \mathrm{ng} / \mathrm{ml})$ for $24 \mathrm{~h}$ in the presence of PAG $(2 \mathrm{mM})$ or saline. These cells were harvested to investigate the changes in the NF- $\mathrm{kB}-\mathrm{Snail}$ pathway. Some cells were subsequently stimulated with TGF- $\beta 1(10 \mathrm{ng} / \mathrm{ml})$ for an additional 9 days to estimate the process of EndMT. Expression of EndMT markers, VE-cadherin and $\alpha$-SMA and signal molecules were examined using (A) western blotting and (B) immunofluorescent staining. Red fluorescence represents VE-cadherin, green fluorescence represents $\alpha$-SMA and blue fluorescence represents DAPI nuclei staining. Scale bar=50 $\mu \mathrm{m}$. (C) The ultrastructure of HPAECs was assessed using TEM. White arrows indicate caveolae. Black arrows indicate WPB. Black triangles indicate microfilaments in the cytoplasm.

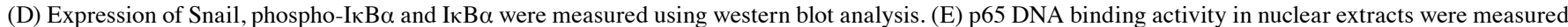
as described in the materials and methods. The data are presented as the mean \pm standard error of the mean of at least three independent experiments. ${ }^{*} \mathrm{P}<0.05$ vs. control group; ${ }^{\# \mathrm{P}}<0.05$ vs. TGF- $\beta 1$-stimulated HPAECs transfected with vector; ${ }^{\circledR} \mathrm{P}<0.05$ vs. TGF- $\beta 1$-stimulated HPAECs transfected with CSE plasmid. CSE, cystathionine $\gamma$-lyase; EndMT, endothelial-to-mesenchymal transition; DAPI, 4,6-diamidino-2-phenylindole; HPAEC, human pulmonary artery endothelial cells; PAG, DL-propagylglycine; WPB, Weibel-Palade bodies; TEM, transmission electron microscopy; TGF, transforming growth factor; NF, nuclear factor; phospho, phosphorylated; VE, vascular endothelial.

In addition to the NF- $\kappa$ B-snail signaling pathway, $\mathrm{H}_{2} \mathrm{~S}$ may affect EndMT/EMT via a variety of mechanisms. In tubular epithelial cells, $\mathrm{H}_{2} \mathrm{~S}$ reduced the expression of TGF- $\beta$ receptor type I and TGF- $\beta$ receptor type II, and attenuated the
TGF- $\beta 1$-induced transduction of extracellular signal regulated kinase and Wnt/catenin pathways, mitigating TGF- $\beta 1$-induced EMT (30). $\mathrm{H}_{2} \mathrm{~S}$ also counteracted TGF- $\beta 1$-induced EMT and exhibited therapeutic potential in renal sclerotic diseases via 
cleaving the disulfide bond in the dimeric active TGF- $\beta 1$ and generating an inactive TGF- $\beta 1$ monomer (29). Furthermore, $\mathrm{H}_{2} \mathrm{~S}$ has been suggested to reserve the epithelial phenotype and inhibit EMT with partial dependence on the Smad and p38 pathways $(31,35,36)$. Collectively, these results establish the important role of $\mathrm{H}_{2} \mathrm{~S}$ in EndMT/EMT, which contributes to numerous conditions, including fibrosis, wound repair, inflammation and malignancy. However, the underlying precise mechanisms and the potential application of $\mathrm{H}_{2} \mathrm{~S}$ in the treatment of these conditions require further study.

In conclusion, the results of the current study demonstrated that $\mathrm{NaHS}, \mathrm{a}_{2} \mathrm{~S}$ donor, exhibits a protective effect on MCT-induced PAH, at least in part, via the reversal of EndMT and impeding pulmonary vascular remodeling. The underlying mechanisms of the inhibitory effect of $\mathrm{H}_{2} \mathrm{~S}$ on EndMT may be dependent on the inactivation of the NF- $\mathrm{NB}$-Snail signaling pathway. These results provide new evidence for the role of $\mathrm{H}_{2} \mathrm{~S}$ in $\mathrm{PAH}$.

\section{Acknowledgements}

Not applicable.

\section{Funding}

The present study was supported by the National Natural Science Foundation of China (grant no. 81570037), Medical Guiding Project of Shanghai Science and Technology Committee (grant no. 19411963300) and Clinical Research Project of Multi-Disciplinary Team, Shanghai Ninth People's Hospital, Shanghai Jiaotong University School of Medicine (grant no. 2017-1-015).

\section{Availability of data and materials}

The datasets used and/or analyzed during the current study are available from the corresponding author on reasonable request.

\section{Authors' contributions}

HuilZ and CW proposed the concept, designed the experiment and revised the manuscript for important intellectual content. HuiZ, YL and YM performed the major experiments. HuilZ wrote the manuscript. JZ analyzed the data and revised the manuscript. All authors read and approved the final manuscript.

\section{Ethics approval and consent to participate}

The protocol was approved by the Committee on the Ethics of Animal Experiments of the Shanghai JiaoTong University School of Medicine [permit no. (2015)-130].

\section{Patient consent for publication}

Not applicable.

\section{Competing interests}

The authors declare that they have no competing interests.

\section{References}

1. Goumans MJ, van Zonneveld AJ and ten Dijke P: Transforming growth factor beta-induced endothelial-to-mesenchymal transition: A switch to cardiacfibrosis? Trends Cardiovasc Med 18: 293-298, 2008

2. Willis BC and Borok Z: TGF-beta-induced EMT: Mechanisms and implications for fibrotic lung disease. Am J Physiol Lung Cell Mol Physiol 293: L525-L534, 2007.

3. Zeisberg EM, Potenta SE, Sugimoto H, Zeisberg $M$ and Kalluri R: Fibroblasts in kidney fibrosis emerge via endothelial-to-mesenchymal transition. J Am Soc Nephrol 19: 2282-2287, 2008.

4. Zeisberg EM, Tarnavski O, Zeisberg M, Dorfman AL, McMullen JR, Gustafsson E, Chandraker A, Yuan X, $\mathrm{Pu}$ WT, Roberts AB, et al: Endothelial-to-mesenchymal transition contributes to cardiac fibrosis. Nat Med 13: 952-961, 2007.

5. Arciniegas E, Frid MG, Douglas IS and Stenmark KR: Perspectives onendothelial-to-mesenchymal transition: Potential contribution to vascular remodeling in chronic pulmonary hypertension. Am J Physiol Lung Cell Mol Physiol 293: L1-L8, 2007.

6. Hopper RK, Moonen JR, Diebold I, Cao A, Rhodes CJ, Tojais NF, Hennigs JK, Gu M, Wang L and Rabinovitch M: In pulmonary arterial hypertension, reduced BMPR 2 promotes endothelial-to-mesenchymal transition via HMGA1 and its target slug. Circulation 133: 1783-1794, 2016.

7. Ranchoux B, Antigny F, Rucker-Martin C, Hautefort A, Péchoux C, Bogaard HJ, Dorfmüller P, Remy S, Lecerf F, Planté S, et al: Endothelial-to-mesenchymal transition in pulmonary hypertension. Circulation 131: 1006-1018, 2015.

8. Lefer DJ: A new gaseous signaling molecule emerges: Cardioprotective role of hydrogen sulfide. Proc Natl Acad Sci USA 104: 17907-17908, 2007.

9. Elsey DJ, Fowkes RC and Baxter GF: Regulation of cardiovascular cell function by hydrogen sulfide $\left(\mathrm{H}_{2} \mathrm{~S}\right)$. Cell Biochem Funct 28: 95-106, 2010.

10. Tang C, Li X and Du J: Hydrogen sulfide as a new endogenous gaseous transmitter in the cardiovascular system. Curr Vasc Pharmacol 4: 17-22, 2006.

11. Hongfang J, Cong Bailin, Zhao Bin, Zhang Chunyu, Liu Xinmin, Zhou Weijin, Shi Ying, Tang Chaoshu and Junbao D: Effects of hydrogen sulfide on hypoxic pulmonary vascular structural remodeling. Life Sci 78: 1299-1309, 2006.

12. Li X, Du J, Jin H, Tang X, Bu D and Tang C: The regulatory effect of endogenous hydrogen sulfide on pulmonary vascular structure and gasotransmitters in rats with high pulmonary blood flow. Life Sci 81: 841-849, 2007.

13. Li X, Du J, Jin H, Geng B and Tang C: Sodium hydrosulfide alleviates pulmonary artery collagen remodeling in rats with high pulmonary blood flow. Heart Vessels 23: 409-419, 2008.

14. Luo L, Liu D, Tang C, Du J, Liu AD, Holmberg L and Jin H: Sulfur dioxide upregulates the inhibited endogenous hydrogen sulfide pathway in rats with pulmonary hypertension induced by high pulmonary blood flow. Biochem Biophys Res Commun 433: 519-525, 2013.

15. Stenmark KR, Meyrick B, Galie N, Mooi WJ and McMurtry IF: Animal models of pulmonary arterial hypertension: The hope for etiological discovery and pharmacological cure. Am J Physiol Lung Cell Mol Physiol 297: L1013-L1032, 2009.

16. Zhang H, Guo C, Wu D, Zhang A, Gu T, Wang L and Wang C: Hydrogen sulfide inhibits the development of atherosclerosis with suppressing CX3CR1 and CX3CL1 expression. PLoS One 7: e41147, 2012.

17. Lin Y, Zeng H, Gao L, Gu T, Wang C and Zhang H: Hydrogen sulfide attenuates atherosclerosis in a partially ligated carotid artery mouse model via regulating angiotensin converting enzyme 2 expression. Front Physiol 8: 782, 2017.

18. Barberà MJ, Puig I, Domínguez D, Julien-Grille $\mathrm{S}$, Guaita-Esteruelas S, Peiró S, Baulida J, Francí C, Dedhar S, Larue L and García de Herreros A: Regulation of Snail transcription during epithelial to mesenchymal transition of tumor cells. Oncogene 23: 7345-7354, 2004.

19. Batlle E, Sancho E, Francí C, Domínguez D, Monfar M, Baulida J and García De Herreros A: The transcription factor snail is a repressor of E-cadherin gene expression in epithelial tumor cells. Nat Cell Biol 2: 84-89, 2000. 
20. Julien S, Puig I, Caretti E, Bonaventure J, Nelles L, van Roy F, Dargemont C, de Herreros AG, Bellacosa A and Larue L: Activation of NF-kappaB by Akt upregulates Snail expression and induces epithelium mesenchyme transition. Oncogene 26: 7445-7456: 2007.

21. Nikitopoulou I, Orfanos SE, Kotanidou A, Maltabe V, Manitsopoulos N, Karras P, Kouklis P, Armaganidis A and Maniatis NA: Vascular endothelial-cadherin downregulation as a feature of endothelial transdifferentiation in monocrotaline-induced pulmonary hypertension. Am J Physiol Lung Cell Mol Physiol 311: L352-L363, 2016.

22. Long L, Crosby A, Yang X, Southwood M, Upton PD, Kim DK and Morrell NW: Altered bone morphogenetic protein and transforming growth factor-beta signaling in rat models of pulmonary hypertension: Potential for activin receptor-like kinase-5 inhibition in prevention and progression of disease. Circulation 119: 566-576, 2009.

23. Zakrzewicz A, Kouri FM, Nejman B, Kwapiszewska G, Hecker M, Sandu R, Dony E, Seeger W, Schermuly RT, Eickelberg O and Morty RE: The transforming growth factor-beta/Smad2,3 signaling axis is impaired in experimental pulmonary hypertension. Eur Respir J 29: 1094-1104, 2007.

24. Reynolds AM, Holmes MD, Danilov SM and Reynolds PN: Targeted gene delivery of BMPR 2 attenuates pulmonary hypertension. Eur Respir J 39: 329-343, 2012.

25. Frid MG, Kale VA and Stenmark KR: Mature vascular endothelium can give rise to smooth muscle cells via endothelial-mesenchymal transdifferentiation: In vitro analysis. Circ Res 90: 1189-1196, 2002.

26. Fan HN, Wang HJ, Ren L, Ren B, Dan CR, Li YF, Hou LZ and Deng Y: Decreased expression of p38 MAPK mediates protective effects of hydrogen sulfide on hepatic fibrosis. Eur Rev Med Pharmacol Sci 17: 644-652, 2013.

27. Fang L, Li H, Tang C, Geng B, Qi Y and Liu X: Hydrogen sulfide attenuates the pathogenesis of pulmonary fibrosis induced by bleomycin in rats. Can J Physiol Pharmacol 87: 531-538, 2009.

28. Jung KJ, Jang HS, Kim JI, Han SJ, Park JW and Park KM: Involvement of hydrogen sulfide and homocysteine transsulfuration pathway in the progression of kidney fibrosis after ureteral obstruction. Biochim Biophys Acta 1832: 1989-1997, 2013.
29. Huang Y, Zhang Z, Huang Y, Mao Z, Yang X, Nakamura Y, Sawada N, Mitsui T, Takeda M and Yao J: Induction of inactive TGF- $\beta 1$ monomer formation by hydrogen sulfide contributes to its suppressive effects on Ang II- and TGF- $\beta 1$-induced EMT in renal tubular epithelial cells. Biochem Biophys Res Commun 501: 534-540, 2018.

30. Guo L, Peng W, Tao J, Lan Z, Hei H, Tian L, Pan W, Wang L and Zhang X: Hydrogen sulfide inhibits transforming growth factor- $\beta 1$-induced EMT via Wnt/Catenin pathway. PLoS One 11: e0147018, 2016.

31. Lv M, Li Y, Ji MH, Zhuang M and Tang JH: Inhibition of invasion and epithelial-mesenchymal transition of human breast cancer cells by hydrogen sulfide through decreased phospho-p38 expression. Mol Med Rep 10: 341-346, 2014.

32. Pan Y, Zhou C, Yuan D, Zhang J and Shao C: Radiation exposure promotes hepatocarcinoma cell invasion through epithelial mesenchymal transition mediated by $\mathrm{H}_{2} \mathrm{~S} / \mathrm{CSE}$ pathway. Radiat Res 185: 96-105, 2016.

33. Ying R, Wang XQ, Yang Y, Gu ZJ, Mai JT, Qiu Q, Chen YX and Wang JF: Hydrogen sulfide suppresses endoplasmic reticulum stress-induced endothelial-to-mesenchymal transition through Src pathway. Life Sci 144: 208-217, 2016.

34. Zhang D, Du J, Tang C, Huang Y and Jin $\mathrm{H}$ : $\mathrm{H}_{2} \mathrm{~S}$-induced sulfhydration: Biological function and detection methodology. Front Pharmacol 8: 608, 2017.

35. Cheng S, Lu Y, Li Y, Gao L, Shen H and Song K: Hydrogen sulfide inhibits epithelial-mesenchymal transition in peritoneal mesothelial cells. Sci Rep 8: 5863, 2018.

36. Fang LP, Lin Q, Tang CS and Liu XM: Hydrogen sulfide attenuates epithelial-mesenchymal transition of human alveolar epithelial cells. Pharmacol Res 61: 298-305, 2010.

This work is licensed under a Creative Commons Attribution-NonCommercial-NoDerivatives 4.0 International (CC BY-NC-ND 4.0) License. 